\title{
ANALYSIS ON STUDENTS' INTERROGATIVE SENTENCE ERROR AT SMA NEGERI 2 SAMALANTAN BENGKAYANG REGENCY
}

\author{
Magpika Handayani ${ }^{1)}$, Yovita Angelina ${ }^{2)}$ \\ 1) Polytechnic of Tonggak Equator Pontianak, Indonesia \\ Email: progressme84@gmail.com \\ 2) Polytechnic of Tonggak Equator Pontianak, Indonesia \\ Email: yovita.angelina89@gmail.com
}

\begin{abstract}
This study aims at identifying the form of questions used by students of SMA Negeri 2 Samalantan Bengkayang Regency, sees errors done by students and describes students' understanding of English interrogative sentence patterns. The location of the research was conducted at SMA Negeri 2 Samalantan Bengkayang Regency because this school is one of the schools that implement the mandatory system of using English in English subjects. In fulfilling these obligations, students often find difficulty in asking in English. The study of interrogative sentences in the students of SMA Negeri 2 Samalantan Bengkayang Regency is a way to solve the problems of students in making interrogative sentences so that learning English activities become easier and students can ask each other questions with correct questions sentence pattern. The method used in this study is describing students' understanding of the interrogative sentences obtained through a list of questions in the form of translation and interviews to determine the form of errors in making questions. The data obtained is then analyzed to obtain the results of research on the difficulties faced by students in understanding the interrogative sentences. The results of this study show the most dominant error in the sentence Yes/No verbs, then Wh-question noun, Wh-type verb type, and the type of sentence Yes/No question nouns. The interview result shows the answers given by the students are consistent with the written answers.
\end{abstract}

Keywords: Analysis; Interrogative Sentence Error; SMA Negeri 2 Samalantan Students

\section{INTRODUCTION}

Making sentences in English is often difficult to understand for students of SMA Negeri 2 Samalantan. In teaching, teachers often find errors in the student's sentence, especially during the conversation. The mistakes often make students not confident and even lazy to learn English. Students often make mistakes in conversation by adopting the first language (Bahasa Indonesia) and translating it into English without understanding the structure of the English language. When teachers ask students to make conversations, many students do not understand the sentence patterns that should be used in the conversation.

One sentence is often used in conversation and is the essence of the conversation itself is an interrogative sentence. An interrogative sentence used in the Indonesian language is translated directly into English language and form a mistake in the pattern of student questions in English. Since it has a pattern of questions that are different from the Indonesian language, asking becomes difficult for students in starting a conversation. Questions that require short answers like "Yes" or "No" have a different pattern than those that require a complete answer. Each question contains a certain meaning and purpose and when it is used erroneously, it will reduce the meaning and intent of the question itself especially in communicating with strangers.

The pattern of questions in Indonesian is often adopted by students who learn English and used as a reference to make English questions. Questions that are made have different goals, especially in terms of intent and content of the question. The source of the problem with errors in making interrogative sentences should be identified in order to solve the students' problems in communicating. With the identification of problems in interrogative sentences, problems in communication can be avoided and students' self-confidence is expected to increase again.

The wrong pattern of interrogative sentences applied by students in English needs to be solved in order to minimize student misconduct. To help teachers solve the problem of 
interrogative sentences of students, an analysis of the factors causing the error should be done. The writer would like to analyze the error of interrogative sentences of SMA Negeri 2 Samalantan students for considering the errors that often occur when the English language. With the analysis of errors in making interrogative sentences in SMA Negeri 2 Samalantan, these errors are expected to be reduced and students' understanding of the interrogative sentences along with its meaning is improved.

In order to support the writing, the writer would like to present the study conducted by the other writers that have similarities and differences with the writer in this writing. The first research was conducted by Abdallah (2000). The research focused on the investigation of negative and interrogative sentence formation. The result of the study found that most students were more difficult to form interrogative sentence than a negative sentence. The difficulties lied in aspects like punctuation, auxiliary, modal auxiliary and context of the sentence. Moreover, Rosyid (2017) conducted research to find out the error made by students in the interrogative sentence. The result of the research showed that there were four aspects in students' interrogative sentence error they are misformation, addition, misordering and omission. The most dominant error is misformation. The research that is going to be conducted in this research is to found out the error that is made by students in the type of sentence both verbal and nominal sentence. The form of verbal and nominal in asking a question is the form of verbal communication that is applied by students that might be different from writing. The result of this writing is expected to add more information about the error in making the interrogative sentence especially on the types of sentence.

\section{LITERATURE REVIEW}

\section{A. English Sentence Pattern}

A sentence is a collection of words consisting of subject and object. The presence of these two parts in English makes the combination of words into a meaningful collection. A sentence can be understood if the subject and predicate support one another. Without a subject or predicate, the unity of the word is not a perfect phrase but a phrase that does not provide complete information. Although only consisting of two elements (subject and predicate), the set of words gives a meaning that can be fully understood because there is synergy between the subject and predicate (Redford, 2009: 7).

Redford (2009: 3) adds that the sentence in the structure of English is usually defined as the composition of words that have a complete understanding. That is, in the sentence, there is a subject element (S), ie the element being discussed. There is a predicate element $(\mathrm{P})$, the element that states what $\mathrm{S}$ element or what the $\mathrm{S}$ element is doing. There may be an element of the object $(\mathrm{O})$, ie the target element of the action performed by the element $\mathrm{S}$. Also there is an element of description (K), ie the element that explains about time, place, way, and so on. Basically, a long sentence can be a simple sentence and vice versa if someone already understands the basis of the sentence.

English sentences also have an arrangement as described above. English sentence has Subject element (s), Predicate (p), Object (o) and Description (k). The elements are served as a major element and those that serve as a complementary element. The main element consists of Subject (S) and Predicate $(\mathrm{P})$ while Object $(\mathrm{O})$ and Description $(\mathrm{K})$ is a complementary element. English sentences usually change in predicate caused by a change of subject called conjugation. Conjugation is the most difficult area for a person to learn English because the changes that occur require a deep understanding in order to make the perfect sentence, (Swick, 2009: 1).

English sentence consists of two parts of the verb sentence and the nominal sentence, (Burton \& Robert, 2010: 9). The structure of the noun and verb is not the same because the verb is a sentence whose predicate is a verb while the noun phrase is a sentence consisting of adjectives and nouns as well as there is auxiliary verb (Auxilliary) between the subject and the compliment.

\section{B. Auxiliary Verb}

An auxiliary verb is a helping verb contained in the structure of an English sentence and is a part that distinguishes the structure of the Indonesian language. Auxiliary verbs basically have no definite meaning, but in certain contexts will give meaning to the context of the sentence. Auxiliary is generally used in Positive sentences and negative sentences as the auxiliary elements of sentence formation. Auxiliary is used as a complementary element so that sentence structure in negative and interrogative can be fulfilled. Here are some examples of sentence formation according to Brown \& Brown (2010: 52).

\section{Positive: I speak English (Verbal sentence) \\ Negative: I do not speak English \\ Interrogative: Do you speak English? \\ Positive: He is diligent (Nominal sentence) \\ Negative: He is not Diligent \\ Interrogative: Is he diligent?}

Greenbaum \& Nelson (2009:39) state:

"Auxiliary verbs (or simply, auxiliaries) come before the main verb in a verb phrase. They consist of two main subclasses, the primary auxiliaries " $b e$ ", "have" and "do", and the modal auxiliaries can, could, will, would, shall, should, may, might and must. In addition, we can distinguish a further subclass of semi-auxiliaries, which include having to (I have to go now), be going to, had better (He had better not be late) and ought to (You ought to take a break)". 
The position of the Auxiliary verb is located before the main verb. Auxiliary verb consists of two main classes namely be, have and do called a primary auxiliary and secondary auxiliary such as, can, will, may, must and so on. Auxiliary is used to help the formation of sentences both negative and interrogative sentences. Auxiliary role in the process of formation of sentences to ask considering its function in the sentence. Brown \& Brown (2010: 52) adds that there are differences in sentence verbs and noun phrases in the auxiliary aspect. The nouns use (is, am, are) as auxiliary or auxiliary verbs in the form of a sentence. While in the sentence the verb "do" and "does" or "did" are used to form each negative and interrogative sentence. Auxiliary verbs serve to help sentence form sentences and as a support in forming a sentence. Without the auxiliary verb, a sentence will not be formed according to the usefulness of the English language. Auxiliary or auxiliary verbs do not require the suffix "s" or "es" in a single third person, (Swick, 2010: 13). A word that requires "s" or "ice" expression occurs in conjugation in the present tense sentence. Auxiliary or auxiliary work serves to help shape negative or positive sentences. Positive sentences are formed by adding the word "Do" or "Does" to the sentence of the verb and "is, am, are" to the numbered sentence.

\section{Interrogative Sentence}

Interrogative sentences are divided into several types of sentences such as sentences that require a short answer and a question sentence that requires a long answer. Sentence question which only requires a short answer formed from auxiliary verbs, while the sentence that requires a long sentence is formed by adding the word auxiliary or commonly called $5 \mathrm{~W}+1 \mathrm{H}$. Both types of sentences of the question has a different purpose from each other and adjusted with the context of the conversation. Yes and No question is often expressed when someone wants to ask something to others and wishes the person to give a short answer yes or no. This type of question is also used to ascertain someone or clarify something that is being done by others or simply to get more information. Therefore, yes or no questions are used to provide brief information that aims to communicate by both parties to work well. The "Yes" or "No" question sentence is given by considering the situation or context of the conversation made by both parties and the yes or no answer is a very correct answer.

Interrogative Sentences that require a long answer given by someone to someone else when someone wants to get more answers than just yes or no is called long answer question. This type of query phrase uses the word auxiliary used to ask the place, time of person, reason and so forth. The sentence of the question with the word auxiliary is used by someone because the information they get is not appropriate or has not fulfilled the requirements. Therefore, the question with the word auxiliary is given so that detailed information can be given and the purpose of communication can be met well because each other understand the meaning and function of the question expressed (Swick, 2009: 109). The formation of a sentence asking with an auxiliary usually requires a short answer "yes" or "no". Auxiliary is placed in front of the subject of the sentence followed by the structure of the other sentence to ask a person for the purpose of obtaining a short answer. Meanwhile, to obtain a more complete answer, the use of $5 \mathrm{~W}+1 \mathrm{H}$ placed in front of the sentence and followed by auxiliary to distinguish the purpose of the question posed. Differences in the question patterns contained in the English language, especially between questions with short answers and questions that require a complete answer should be understood to avoid misunderstanding in interpreting the meaning of questions, (Greenbaum \& Nelson, 2009: 39).

\section{First Language Interference}

It is frequently found that in the process of learning a foreign language a learner is affected by the first language or mother tongue because one tends to acquire language indirectly than programmed, (Han \& Rast, 2014: 42). The first language has a very strong influence on the process of learning a foreign language like English. To avoid a significant first-language influence on a foreign language being learned, one needs to understand the structure of the learned language sentence and see the difference between the two languages. With the understanding of the differences, students are expected to form a foreign language in accordance with the language structure and not influenced by the first language or mother tongue.

According to Han \& Rast (2014: 42), the first language has a significant influence on the development of foreign languages being studied because the first language is a language that is always used and already fossilized for someone who is learning a foreign language. The first language can be used as a reference for someone to develop their foreign language by comparing patterns and understanding the patterns and see what is in the foreign language sentence and how their first language sentence pattern. To gain that understanding, one must often train their foreign languages so that the learned language can be used in the correct context and familiar with the pattern.

According to Turnbull \& O'Cain (2009: 22), the first language affects the foreign language sentence patterns learned by students and causes confusion for students. The first language is a factor that affects the existence of errors when having a conversation. However, not all first language patterns or habits are different from those in the second language. There is a possibility that the means of expressing a meaning are the same in both the first language and the second language. In this case, the learning person does not need to cope with proactive barriers, in which case errors occur. Transfers are positive when the first language and the second language have the same habits. In this case, there will be no errors. Thus, the differences between the first language and the second language will create learning difficulties in the form of error, whereas the equations between the first language and the second language facilitate the learning effort quickly and easily.

Mistakes in language learning are a result of the unevenness and the consequences of mistakes. Both of these 
give full conformity that mistakes should be avoided and kept away. The simplest comparison and procedures are about which aspects of the two are concurrent and which are different. However, it appears that there are levels of similarities and differences. Every learner who learns language often misbehaves when what is learned does not match what should be done in this case is practiced. When a person is able to realize his mistake in learning, then the way to solve the error will be solved, however, if someone is unaware of any mistakes made while using the language, then the tiredness will become a habit that continues to be wrong (Turnbull \&O'Cain, 2009: 22).

\section{METHODOLOGY}

Given the issues discussed in this study, the appropriate method is descriptive research method by describing the students' problems inductively and collecting information on the problems encountered, (Lodico \& Voegtle, 2010: 142). By doing this research, the author intends to provide an overview of the problems faced by students of SMA Negeri 2 Samalantan, Bengkayang Regency. The number of students in SMA Negeri 2 Samalantan Bengkayang Regency is 100 students. In this study, 40 students as a sample were taken to represent the existing population.

\section{A. The technique of Data Collecting}

The writer gives a written test in the form of a sentence question in the Indonesian language to be translated into English. Then to ensure that the students' answers really represent their knowledge, the author will interview the students so that the information obtained through the written test in accordance with the real knowledge of students about the sentence questions in English. The author once again gives some sample Indonesian sentence questions and the students convert the sentence in English to ensure the information provided by the students is correct, (Lodico \& Voegtle, 2010: 123).

\section{B. The instrument of Data Collecting}

The instrument of Data collecting in this research is a test in the form of sentence questions and interview sheets. Borg \& Gall (2007: 222) test is a measure used to see students' abilities or mistakes. In this study, the writer made a list of interrogative sentences made in Indonesian language and students are asked to change the sentence into English so that the writer can get initial information about student mastery of the interrogative sentence. The results of the test are analyzed and grouped by the type of sentence the question is. Interview sheet is a tool used to obtain information from students by interview. Interviews were conducted to find out more in the problems faced by undetected students through mistakes made by students on the written test, (Lodico \&Voegtle, 2010: 126).

\section{RESULTS AND DISCUSSION}

\section{A. The Result of Test}

The two previous studies conducted by Abdallah (2000) and Rosyid (2017) were to analyze the error in students' sentence and to know the sentence that is more difficult to make by students. The previous study showed that there were four aspects in students' interrogative sentence error they are misformation, addition, misordering and omission and the most dominant error is the misformation. Moreover, most students were more difficult to form interrogative sentence than a negative sentence. The study in this research focused on finding students interrogative sentence error in the type of sentences like verbal and nominal. The discussion of the finding is shown as follow.

The results of data analysis are shown in Fig. 1 and is a general overview to see the number of students who make the wrong sentence, the number of students who make the sentences correctly, the number of students who make sentences with tenses that are not appropriate, the number of students who make sentences incomplete questions or number of students who did not give an answer in making interrogative sentences.

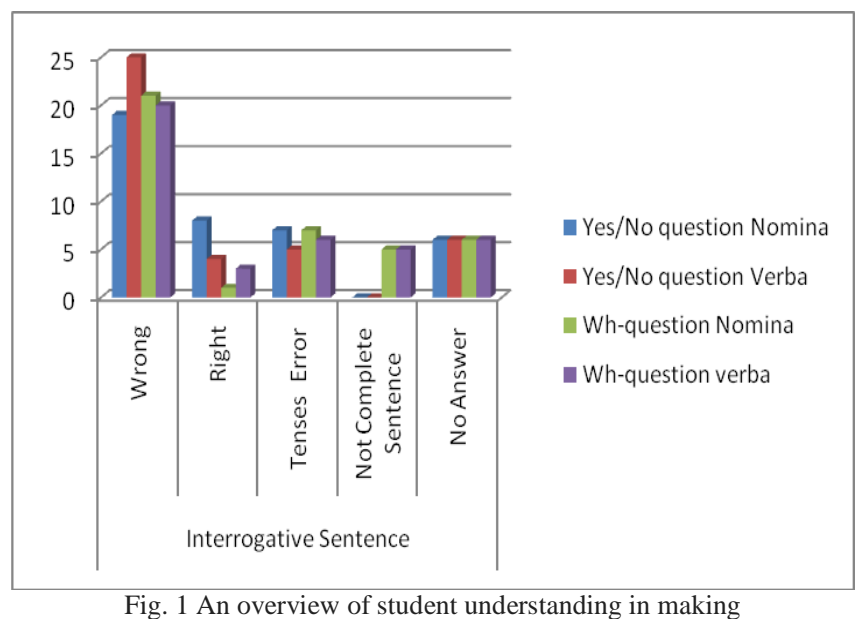

Fig. 1 An overview of student understanding in making interrogative sentences

It is obvious the graph above that the percentage of errors as a whole where it can be seen from the percentage of the most dominant to the less dominant. This shows that students as a whole do not understand how to make interrogative sentences in English. The following is explained on what type of sentence each error occurs. First, the most dominant error is in the sentence Yes/No verbs shown in brown. Errors students make in this section is the use of auxiliary words that are not in accordance with the question Yes/No question verbs. Students tend to use auxiliary words (is, am, are) to compose short sentences in verb form. Second, the error that occurs after the Yes/No question verb is Wh-question noun where students cannot make sentences with the correct pattern and sentences that are made tend to be confusing because it is not in accordance with English grammar. It can be seen in green on the graph. A third error occurs in the Wh-question verb 
type of the sentence indicated by the purple color of the graph. Sentences made by students tend to follow the Yes/No question sentence pattern and some do not use the query word. Fourth, the error in making the sentence of the question occurs on the type of sentence Yes/No question nouns are shown in blue on the graph. In this section, students can not make sentences correctly and with the correct grammar. The mistake made by the student is not using the correct auxiliary to make the question because the auxiliary word used does not match the word auxiliary of nominal sentence.

\section{B. Interview Result}

The interview is one way to obtain information from students by digging information in depth. Interviews in this study were conducted to find out more in the problems faced by students who were not detected through errors made by students on written tests. Interviews in this study were conducted in two stages; stage 1 interview was conducted on April 28, 2018. Interviews were conducted with students of class XI IPA consisting of 20 students. From the results of interviews conducted with students both class XI IPA and XI IPS, the authors compare the answers given in writing or orally. The answers were given by the students either in writing or verbally lead to a consistency where the author sees the student's answers during the interview. This means that students' understanding of the interrogative sentences does not change either in writing or orally. Of the 40 students interviewed, there were few different answers but not substantive answers.

\section{CONCLUSION AND SUGGESTION}

From the results of the analysis conducted on students of class XI IPA and IPS SMA N 2 Samalantan, the writer concluded that the understandings of SMA N 2 Samalantan students in making interrogative sentence are as follows:

\section{A. Conclusion}

The most dominant mistake is the sentence Yes/No verbs are shown with brown color. Errors students make in this section is the use of auxiliary words that are not in accordance with the question Yes/No question verbs. Students tend to use auxiliary words (is, am, are) to compose short sentences in verb form. This error resulted in the student's elusive sentence and the purpose of the question becoming unclear. Errors that occur after Yes/No question verbs are Wh-question nouns where students cannot make sentences with the correct pattern and sentences that are made tend to be confusing because it is not in accordance with English grammar. It can be seen in green on the graph. The student tendency to generalize the sentence of the question with the same pattern by using is (is, am, are). An error occurs in the Wh-question verb type sentence indicated by the purple color of the graph. Sentences made by students tend to follow the Yes/No question sentence pattern and some do not use the query word. The error in making the sentence of the question occurs on the type of sentence Yes/No question nouns shown in blue on the graph. In this section, students cannot make sentences correctly and with the correct grammar. The mistake made by the student is not using the correct auxiliary to make the question because the auxiliary word used does not match the word auxiliary sentence nominal.

\section{B. Suggestion}

The teacher should first identify the problems of students before giving subject matter, especially material about functions and the use of verbs to help compare the understanding of the rest before and after the explanation. The teacher should explain the differences in verb sentences and noun sentences in a sentence because students cannot distinguish the differences and tend to use one of these auxiliary verbs. The teacher is expected to explain the differences in short sentences that require the answer "yes" or "No" with questions that use question-assisting words such as why, when, where, who, what and how which tend to require more complex answers. The practice of asking questions and answering questions must be done as often as possible in the classroom to shape students' habits in asking questions and answering questions. The school is expected to provide motivation by holding an internal English language competition so students get used to English. Internal competition might improve students' understanding and introduce English intensively to students.

\section{REFERENCES}

Abdallah, Jamal Jafar Ahmed. (2000). An Analysis of Negative and Interrogative Formation Errors in English Language: A Case Study of Damazeen Technological College Students. Thesis: University of Khartoum.

Borg, Walter R \& Gall, Meredith. (2007). Educational Research. Pearson. USA.

Brown, Caroline \& Brown, Pearson. (2010). English Grammar Secret. Macmillan Education.

Burton \& Robert. (2010). Analysing Sentence. An Introduction to English Syntax. Routledge. New York.

Gelderen, Elly Van. (2010). An Introduction to the Engish Grammar. Revised edition. John Benjamin. Netherlands.

Greenbaum, Sidney \& Nelson, Geral. (2009). An Introduction to English Grammar. Third Edition. Routledge. New York. USA.

Han, Zhoa Hong \& Rast, Rebekah.(2014). First Exposure to a second language. Learners' initial input processing. Cambridge University Press.UK.

Lodico, Marguerite G \& Voegtle, Katherine H (2010).Methods in Educational Research. From Theory to Practice. San Francisco. USA.

Mulyatinigsih, Endang. (2013). Metode Penelitian Terapan Bidang Pendidikan. Alfabeta. Bandung.

Redford, Andrew. (2009). An Introduction to English Sentence Structure. Cambridge University Press. New York. 
Rosyid, Muhammad. (2017). The Error Analysis In Interrogative Sentences Made By The Eleventh Grade Students of SMK Batik Perbaik Purworejo in the Academic Year of 2016/2017. Thesis. English Education Program Teacher Training and Education Faculty Purworejo Muhammadiyah University. Purwerejo.

Swick, ED. (2009). Writing Better English. For ESL Learners. Second Edition. McGraw-Hill. New York.

.(2010). Verb and Essential Grammar. For ESL Learner. McGraw-Hill. New York.

Turnbull, Miles \& O'Cain, Jennifer Dailey. (2009). Second Language Acquisition. First language use in second and foreign language learning. Multilingual matter. UK. 